is intricate, and not one in which it is easy to excite interest in a general audience. It is, therefore, much to the lecturer's credit that he succeeded in making the subject not only intelligible, but also interesting. He discussed first Froude's theory of the screw, and then showed how the various factors in the resulting equations had been checked by experimental work both in the wind-channel and on the "rotating arm" apparatus. Incidentally, he referred to the flapping flight of birds, showed how difficult it would be to imitate this, and doubted whether true progress lay in this direction. Mankind had made much use of the wheel in mechanism; evolution had led to the introduction of no such element in animal life, in spite of its proved efficiency in its many human applications. This afforded an argument that man had here beaten uninstructed Nature. The only flying animal which approached the aeroplane in design was perhaps the beetle, which possibly used its horny wing-covers as stationary planes and its wings as a means of propulsion.

\section{The Parallaxes of Globular Clusters and Spiral Nebulæ.}

IT may be remembered that Dr. Charlier expressed doubt as to the correctness of the enormous distances for globular clusters announced by Dr. Harlow Shapley. Mr. Knut Lundmark, of Upsala Observatory, undertook a re-examination of the question, taking different lines of evidence from those used by Dr. Shapley. His work is published in Kungl. Svenska vetenskapsakademiens Handlingar, Band 6o, No. 8. His data are avowedly of a much less precise character than those used by Dr. Shapley, but they lead to results of the same order of magnitude :-

(I) The discussion of the proper motion of those clusters for which data are available indicates a value not exceeding $I^{\prime \prime}$ per century. Accepting this maximum value, and combining it with the mean radial velocity of clusters found by Prof. Slipher, Mr. Lundmark finds the distance 3000 parsecs, one-fifth of Dr. Shapley's value.

(2) Use is made of Kapteyn's luminosity law. Van Schouten has already applied this method to the clusters $\mathrm{M}_{3}, 5$, II, and $\mathrm{I}_{3}$, obtaining distances that are, in the mean, twenty-eight times those of Dr. Charlier and one-eighth of those of Dr. Shapley. His work is here revised, estimation being made of the spectral type of the stars from Dr. Shapley's observed colour-indices. The mean of several independent estimations gives 6000 parsecs for the distance of $\mathrm{M}_{3}$ and $\mathrm{M}_{13}$.

(3) A rough estimate of distance is made from the observed mean absolute magnitudes of stars of different spectral types. Various assumptions are made as regards the mean spectral type of the stars employed. In the mean the distances found are about eighty times those of. Dr. Charlier, or one-third of those of Dr. Shapley.

(4) Holetschek has investigated the apparent magnitudes of several clusters regarded as single objects. Mr. Lundmark shows that his values are about il magnitudes brighter than Dr. Shapley's mean values of the twenty-five brightest stars in the respective clusters, this difference being very nearly constant.

It follows that the assumption that the absolute magnitude of a cluster is constant will lead to relative distances of the different clusters proportional to those deduced by Dr. Shapley.

The four lines of evidence outlined above, though No. 2633 , VOL. IO5] individually weak, have cumulative force, and tend to increase confidence in the accuracy of Dr. Shapley's work.

Mr. Lundmark uses Prof. Slipher's radial velocities of clusters to determihe the sun's motion with regard to them. He finds that its velocity is $38 \mathrm{I} \mathrm{km}$. $/ \mathrm{sec}$ towards R.A. $320^{\circ}$, N. decl. $74^{\circ}$. He notes that both the R.A. and declination of the solar apex as determined from stars tend to increase as fainter stars are used. This is explained by a larger proportion of the stars being outside the local cluster. He suggests that his value is the limit to which the others are tending.

Mr. Lundmark passes on to consider the parallaxes of the spiral nebulæ.

(I) Beginning with the Andromeda nebula, he quotes all the directly observed measures of its parallax. They are discordant, but their mean is near zero.

(2) The star density increases towards the middle of the Andromeda nebula, in spite of the nebulosity tending to veil them. It is concluded that the nebula is more distant than the non-nebular faint stars in the region. A combination of the results of many workers indicates a distance of 3000 parsecs for these faint stars.

(3) A combination of measured angular rotation of spirals with the values of the linear rotational speed given by the spectroscope has led to estimates of distance somewhat greater than the last, say 4000 parsecs. It is further shown that the mass necessary to control the rotation is $10^{\circ} \times$ sun, of the same order as the estimated mass of the stellar system.

(4) Making the rather doubtful assumption that the dark curves in various nebulæ have the same absolute dimensions as the similar dark regions in the galaxy, Wolf finds distances for various spirals ranging from Io, 000 to 200,000 parsecs.

(5) Comparisons of the light curves of novæ in spirals with those in the galaxy, while they involve several rather doubtful assumptions, give very large distances for the spirals, 200,000 parsecs being found for the Andromeda nebula. Bullialdus noted that the Andromeda nebula was exceptionally bright in the year 1664. It is conjectured that a nova of magnitude 5 or 6 may have appeared in it at that time.

From the above and other considerations Mr. Lundmark locates the spiral nebulæ far beyond the galactic limits, but inclines to the view that they are the starproducing mechanisms of Mr. Jeans's theory rather than counterparts of the galaxy. Their linear dimensions appear to be much inferior to the latter, of which our ideas have lately been enlarged by Dr. Shapley's and other researches.

\section{The Forestry Commission.}

WE are informed that the Forestry Commissioners who were appointed on November 29 last at once proceeded with the planting programme for 1919-20. The shortage of forest-tree seed has been met to a great extent by purchases in Austria and elsewhere and by gifts from the United States and Canada. About 34,000 acres of afforestable land are in course of acquisition by purchase or on lease, in some cases below the market value and in others as free gifts from landowners. Rather more than 10,000 acres are in England, of which 3500 are in Suffolk, 2760 in Devon, 1150 in Cumberland, and 1800 in Northamptonshire and Bedfordshire. More than 5000 acres are in Ireland, of which 2000 are in Tyrone, ${ }_{5} 5^{\circ}$ in County Galway, ${ }^{1} 5^{\circ 0}$ in King's County, and 
the remainder in County Cork. The remaining 18,000 acres under acquisition are in Scotland. Planting is proceeding at thirteen centres-six in England and Wales, six in Scotland, and one in Ireland. Statistical work is being carried out and preliminary surveys are being undertaken.

The scheme for advances under the Forestry Act will be published after the consultative committees which have just been set up have considered the proposals.

Forest apprentices are receiving a two-year course in the Forest of Dean, the New Forest, and in Chopwell Woods, near Newcastle, and additional schools will be opened during the year. A special course for men with previous forestry experience is being conducted at Marischal College, Aberdeen.

An Imperial Conference to consider the forest resources and policy of the Empire is being organised for July, when a number of persons interested in forestry are expected in this country for the British Empire Timber Exhibition. The conference is expected to lead to the establishment of an Imperial Bureau of Forestry Information.

The Commission has published Bulletin No. I, "Collection of Data as to the Rate of Growth of Timber" (which can be obtained post free for $4 \frac{2}{2} d$. on application at the headquarters of the Commission, 22 Grosvenor Gardens, London, S.W.I); also Leaflet No. I, "Pine Weevils" (free). Other publications will follow at an early date.

The four consultative committees under the Forestry Act have been appointed, and consist of the following members:-

England.--Lt.-Col. G. L. Courthope (chairman), Col. M. J. Wilson (vice-chairman), Sir J. Ball, Lord Henry C. Bentinck, E. Callaway, the Earl of Chichester, M. C. Duchesne, I. H. Green, W. A. Haviland, Sir Edward Holt, Bart., E. C. Horton, A. F. Luttrell, W. Peacock, Major Harold Pearson, Col. B. J. Petre, Thomas Roberts, Sir William Schlich, W. R. Smith. Charles Stewart, Sir Lawrence Weaver, Col. J. W. Weston, and Leslie S. Wood.

Wales.-The Lord Kenyon (chairman), Col. F. D. W. Drummond (vice-chairman), C. B. Bovill, Major David Davies, Alderman T. W. David, Col. J. R. Davidson, Capt. J. D. D. Evans, Col. W. Forrest, Vernon Hartshorn, G. A. Humphreys, C. Bryner Jones, J. Jones, Lt.-Col. W. N. Jones, Col. C. V. Llewellvn, F. I. Mathews; the' Earl of Powis, L. R. Pym: D. C. Roberts, J. Roberts, Major-Gen. A. E. Sandbach, J. I. Storrar, the Lord Tredegar, H. C. Vincent, P. Wilkinson, and Col. Sir H. L. WatkinWilliams-Wynn, Bart.

Scotland.-Sir Hugh Shaw-Stewart, Bart. (chairman), Gen. Stirling of Keir (vice-chairman), the Right Hon. William Adamson; Sir Isaac Bavley Balfour, F. R. S. Balfour, Wm. Black, Gilbert Brown, J. C. Calder, Sir Isaac Connell, J. A. Duthie, G. Fraser, R. Galloway, S. J. Gammell, Sir Robert Greig, J. H. Milne Home, G. Leven, Sir Robert Lorimer, H. L. Macdonald, Sir Kenneth I. Mackenzie; Bart., J. T. McLaren, J. Matson, D. Munro, Major W. Murray, J. Scott, and J. Wight.

Ireland.-T. B. Ponsonby (chairman), H. De F. Montgomerv (vice-chairman), E. M. Archdale, J. Bagwell, the Lord Osborne Beauclerk, R. Bell, R. Bradley, S. Brown, J. R. Campbell. St. Clair M. Dobbs. Sir Henry Doran, J. Everett, V. C. Le Fanu, Wm. Field, A. C. Forbes, J. Calvin, the Earl of Granard, Prof. Augustine Henry, Wm. Kirkpatrick, A. E. Moran, the Viscount Powerscourt, the Viscount de Vesci, A Vincent, Capt. R. H. Prior Wandesforde, and the Right Hon. F. S. Wrench.

No. 2633 , VOL. IO5]

\section{Recent Fishery Investigations. ${ }^{1}$}

FIVE years ago the pivot round which fishery inves tigation turned was the question of the productivity of the North Sea grounds. It was agreed that the enormous development of catching power since the last third of the nineteenth century had produced no apparent change in the abundance of herring, had. dock, whiting, and possibly some other species, but that, on the other hand, plaice, sole, turbot, and some other edible fishes had been affected. In January, rgI3, the Plaice Committee of the International Fishery Council stated that it then had evidence that large plaice were becoming scarcer in the North Sea, and that small plaice were becoming more abundant, and this was taken to be proof that there was "impoverish ment," or excessive exploitation of a natural resource. The conclusion is not free from ambiguity, for, on the whole, the total quantity of fish landed increased up to I9I3; what had happened, it appears, was a reduction in the average expectation of life of a plaice living in the North Sea. Now if that change was a result of "intensive" fishing up to 1914 , what has been the result of the very great decrease in fishing during the years 1915-18? Drs. A. C. Johansen and Kirstine Smith seek to answer this question by discussing measurements of plaice landed from a Danish North Sea area which was tolerably free from military restrictions during the period of war. They find that the pre-war tendency has been reversed; that large plaice are now relatively much more abundant than they were, but that their rate of growth has decreased-a curious result. We were justified, they say, in concluding that intensive fishing could reduce a natural stock of fish, and we are also justified in expecting that a slackening of this intensity of fishing, even for a relatively short period, will have the opposite effect.

The method by which the latter conclusion is made is indirect, and one is scarcely convinced that it is beyond doubt. It seems easy to show whether or not a natural fishery is stationary or declining. It would be easy and the conclusions certain if the systems of collecting statistics were adequate and well planned and if there were good scientific investigations that enabled one to interpret the statistical data. But the statistics are not adequate, and the scientific investigations have been neither well planned nor properly supported, and therefore the methods are roundabout ones and the conclusions do not carry absolute conviction We do not know, for instanoe, that there is not a natural periodicity of abundance and that the results noticed do not simply represent phases in a cyclic change. It is quite likely that they do.

The last report of the Dove Marine Laboratory (at Cullercoats, Northumberland) contains an account (by Mrs. Dorothy Cowan and Mr. B. Storrow) of investigations into the local herring fishery. This and former reports contain a very rich series of data with regard to the biology of the herring on the North East coast; and apparently not all the results obtained have been published-the present report, for instance, deals only with age-determinations (by means of "scale-readings"), while binmetric measurements made as part of the Board of Agriculture and Fisheries scheme of racial investigations have also been accumulated. Prof. Meek, in editing the report, points out that extensive accumulations of data have not yet been analysed, and that such treatment is advisable before further investigations are planned. His discussion of some of $\mathrm{Mr}$. Storrow's results gives point to an expression of dis.

1 "Meddelelser fra Kommissionen for Havunder sozelser; Ser Fiskeri," Bd. v., Nr. 9. (Copentragen', r9t9.) 